\title{
Florística e estrutura de um trecho de mata ciliar do rio Carinhanha, Feira da Mata, Bahia, Brasil
}

\author{
Francisco Sanches Gomes \\ Maria Lenise da Silva Guedes \\ Romeo de Medeiros Valadão \\ Ana Raquel Santos Prates \\ Maria Auxiliadora de Andrade Costa * \\ Universidade Federal da Bahia, Instituto de Biologia, Departamento de Botânica \\ Rua Barão de Geremoabo, s/n, Campus Universitário de Ondina \\ CEP40171-970, Salvador - BA, Brasil \\ * Autor para correspondência \\ doramaria00@yahoo.com.br
}

\section{Resumo}

O objetivo deste trabalho foi contribuir para o conhecimento da composição florística e estrutura da vegetação de um trecho de mata ciliar, às margens do rio Carinhanha, pertencente à bacia do rio São Francisco, em um fragmento de Cerrado lato sensu, em Feira da Mata, Bahia. Foram alocados quatro transectos de $50 \mathrm{~m}$, equidistantes entre si, e 12 parcelas de $10 \mathrm{~m}$ x $25 \mathrm{~m}$, distribuídas entre os transectos, totalizando $3.000 \mathrm{~m}^{2}(0,3$ ha). Todos os indivíduos vivos e mortos com DAP $\geq 5 \mathrm{~cm}$ foram amostrados. No levantamento florístico, foram amostradas 105 espécies, 87 gêneros e 42 famílias. No estudo fitossociológico foram registrados 217 indivíduos distribuídos em 54 espécies, 49 gêneros e 29 famílias. A família com maior riqueza de espécies foi Fabaceae, que incluiu $24,07 \%$ do total de espécies amostradas. A espécie Oxandra reticulata Maas apresentou o maior valor de importância. A densidade foi 723 indivíduos.ha-1 e a área basal 14,52 $\mathrm{m}^{2} \cdot \mathrm{ha}^{-1}$. O índice de diversidade de Shannon-Wiener (H`) foi 3,62. O índice de Sørensen (Sø) evidenciou baixa similaridade com outros fragmentos de mata ciliar do Cerrado. Concluiu-se que a área estudada compartilha espécies com outras fisionomias do Cerrado e contém espécies da Caatinga, confirmando a heterogeneidade dessa formação.

Palavras-chave: Bacia do rio São Francisco; Cerrado; Diversidade

\section{Abstract}

Floristics and structure of a stretch of riparian forest in Carinhanha river, Feira da Mata, Bahia. This study aimed to contribute to understanding the floristic composition and vegetation structure of a stretch of riparian forest on the banks of Carinhanha river, belonging to the São Francisco river basin, in a fragment of Cerrado sensu lato, in Feira da Mata, Bahia, Brazil. Four equidistant $50 \mathrm{~m}$ transects were placed, as well as twelve $10 \mathrm{~m}$ x $25 \mathrm{~m}$ plots, distributed among transects, totaling 3,000 $\mathrm{m}^{2}(0.3 \mathrm{ha})$. All live and dead individuals with $\mathrm{DBH} \geq 5 \mathrm{~cm}$ were sampled. In the floristic survey, a total of 105 species, 87 genera, and 42 families were sampled. In the phytosociological study, a total of 217 individuals distributed into 54 species, 49 genera, and 
29 families were registered. The family having the greatest species richness was Fabaceae, which included $24.07 \%$ of all species sampled. The species Oxandra reticulata Maas showed the greatest importance value. The density was 723 individuals.ha-1 and the basal area was $14.52 \mathrm{~m}^{2}$.ha-1. Shannon-Wiener's diversity index (H') was 3.62. Sørensen's index (Sø) showed low similarity with to other riparian fragments. We concluded that the area under study shares species with other Cerrado physiognomies and it has species from Caatinga, something which confirms the heterogeneity of this formation.

Key words: Cerrado; Diversity; São Francisco river basin

\section{Introdução}

OCerrado ocupa cerca de $22 \%$ do território nacional, e é considerado o segundo maior bioma brasileiro depois da Floresta Amazônica (PAGOTTO et al., 2006; MMA 2013). Nos últimos anos o bioma, que apresentava uma área de 204 milhões de hectares, teve 57\% de sua cobertura original reduzida, devido, principalmente, à expansão agrícola (KLINK; MACHADO, 2005). Essa perda de cobertura vegetal, aliada aos altos níveis de endemismos para os diversos grupos biológicos, fez com que o Cerrado fosse considerado um hotspot (MYERS et al., 2000; SARMENTO; SILVA JÚNIOR, 2006; SIMON et al., 2009).

O Cerrado apresenta variadas fitofisionomias, como campo limpo, campo sujo, cerrado sensu stricto, cerradão e as matas ciliares (RIBEIRO; WALTER, 2008). Dentre essas fitofisionomias, as matas ciliares destacam-se por apresentarem interfaces com outros tipos de vegetação, como as florestas ombrófilas e mesofíticas, o que resulta na heterogeneidade ambiental e diversidade biológica propiciada pela natureza ecotonal da mata ciliar (OLIVEIRA-FILHO; RATTER, 2001; RODRIGUES; NAVE, 2001; COUTINHO, 2002; MATOS; FELFILI, 2010). As matas ciliares são importantes na manutenção da integridade dos ecossistemas e representam valorosas áreas de preservação de espécies animais, vegetais e dos recursos naturais (KAGEYAMA; GANDARA, 2001). Possuem, ainda, o papel de reduzir o impacto das águas no solo e de aumentar a capacidade de retenção de água ao longo da bacia hidrográfica (STOCKAN et al., 2012).

A bacia do São Francisco contempla fragmentos dos biomas Floresta Atlântica, Cerrado e Caatinga.
O Cerrado cobre praticamente metade da área desta bacia, entre o estado de Minas Gerais e oeste da Bahia (CBHSF, 2006). O rio Carinhanha é um dos afluentes perenes do rio São Francisco e faz parte da região denominada Médio São Francisco; esse rio percorre vários municípios dos estados da Bahia e Minas Gerais, fazendo a divisa entre esses dois estados. Com papel importante na economia local, o uso intensivo das áreas próximas à foz ameaça a biodiversidade local (SANTOS; VIEIRA, 2005). Devido ao avanço da monocultura nestes estados, principalmente no estado da Bahia, houve grande redução das matas ciliares nessa região, o que ocasionou processos erosivos nas margens dos rios, dificultando as tentativas de revitalização (ZELLHUBER; SIQUIERA, 2007).

Assim, faz-se urgente a necessidade de estudos que avaliem a diversidade biológica contida nestes fragmentos, por meio de sua quantificação e organização espacial (CARVALHO et al., 2005). Neste sentido, os levantamentos fitossociológicos são de grande importância para compreender a composição florística, a estrutura e como estão distribuídas as espécies vegetais, para avaliar os impactos antrópicos, planejar possíveis Unidades de Conservação e a adoção de técnicas de manejo (FELFILI; SILVA JÚNIOR, 2001).

Os objetivos deste trabalho foram conhecer a composição florística e estrutura da vegetação de um trecho de mata ciliar, no município de Feira da Mata, Bahia, comparar estruturalmente os resultados encontrados com o de outras áreas de mata ciliar do domínio do Cerrado e contribuir para o aumento do conhecimento da flora do estado, na expectativa de gerar subsídios para futuros projetos de conservação e recuperação de remanescentes. 


\section{Material e Métodos}

A área de estudo está inserida na margem do rio Carinhanha, no município de Feira da Mata, no sudoeste do estado da Bahia, entre as coordenadas $14^{\circ} 13^{\prime} 54,7^{\prime \prime} \mathrm{S}$ e $44^{\circ} 12^{\prime} 45,3^{\prime \prime} \mathrm{W}$, com altitude de 469 m (Figura 1). A época de seca na região ocorre no período mais frio: junho, julho e agosto (INMET, 2013). O clima do município, segundo a classificação de Köppen, é do tipo Aw, com precipitação média de $859,48 \mathrm{~mm} /$ ano e temperaturas médias de $11,5^{\circ} \mathrm{C}$ a $22,0^{\circ} \mathrm{C}$ (ANA, 2005).

A bacia do Rio Carinhanha apresenta pouca variação de tipos de solo, predominando em boa parte da área os Latossolos Amarelos Distróficos, mas são encontrados também Neossolos Quartzarênicos Órticos e Latossolos Vermelho-Amarelos Distróficos (EMBRAPA, 2011).

FIGURA 1: Localização geográfica do município de Feira da Mata, Bahia, podendo ser notados o rio Carinhanha e a bacia do rio São Francisco.

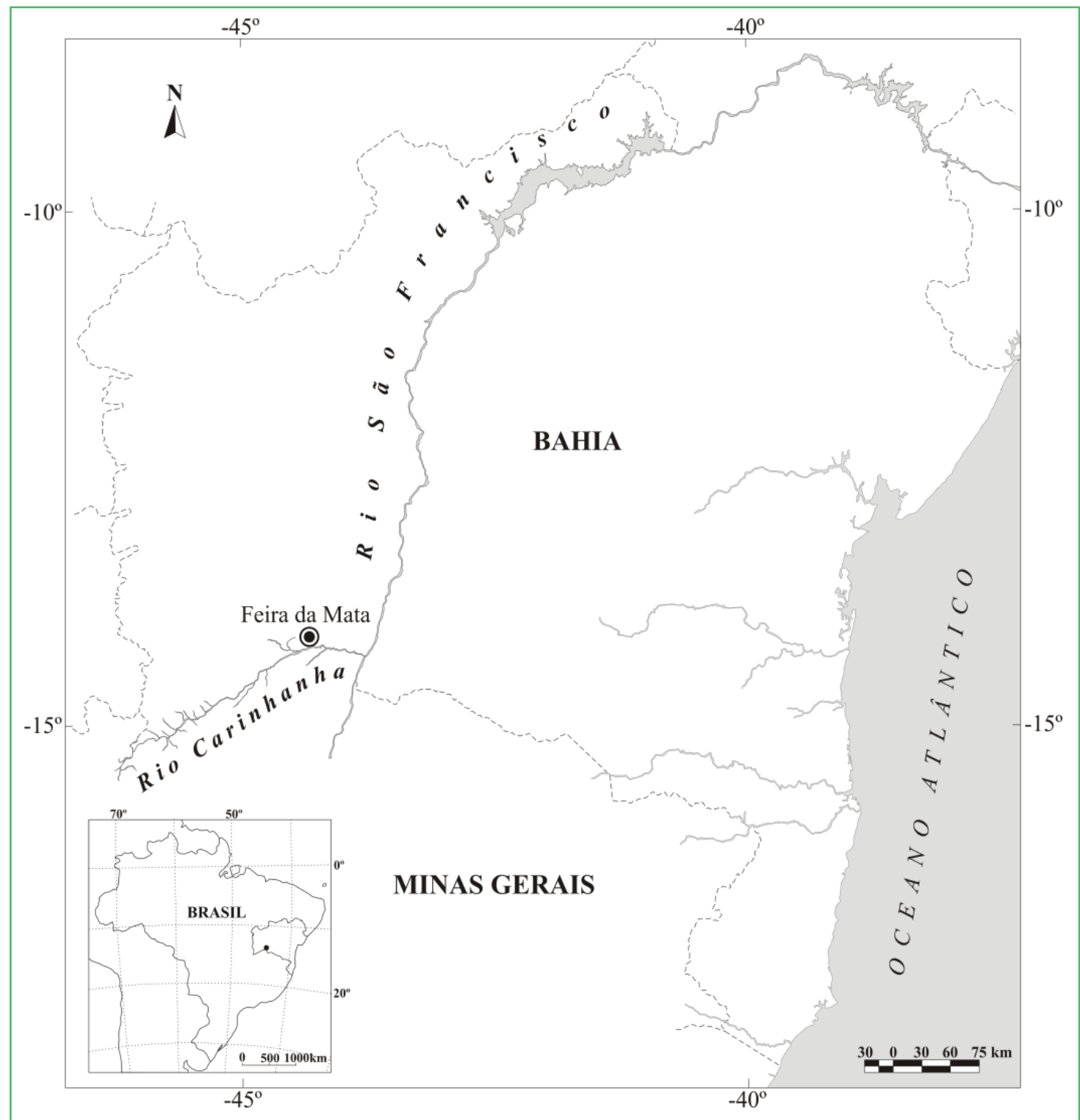


As coletas foram realizadas no período de maio de 2007 a janeiro de 2008. Para o estudo fitossociológico foram implantados, na margem esquerda do rio, quatro transectos de $130 \mathrm{~m}$ cada, dispostos perpendicularmente ao leito do rio e equidistantes entre si, por $50 \mathrm{~m}$ em linha reta. O comprimento dos transectos foi definido em função do leito do rio. Em cada transecto foram alocadas três parcelas de $10 \times 25 \mathrm{~m}$, equidistantes $50 \mathrm{~m}$ entre si, totalizando 12 parcelas, correspondendo a uma área amostral de 0,3 ha. Todos os indivíduos vivos e mortos com diâmetro à altura do peito (DAP) $\geq 5 \mathrm{~cm}$ foram amostrados. Considerou-se morto o indivíduo em pé, com caule oco e sem seiva circulante.

Para o levantamento florístico, foi utilizado o método de caminhamento (FILGUEIRAS et al., 1994). Todo o material botânico coletado foi identificado por consulta à literatura especializada e por comparação com o existente nos acervos dos Herbários Alexandre Leal Costa (ALCB), RADAMBRASIL (HRB) e da Universidade Estadual de Feira de Santana (HUEFS), todos localizados no estado da Bahia. Os espécimestestemunho foram incorporados ao acervo do Herbário ALCB e as duplicatas enviadas ao HUEFS. As abreviações dos nomes dos autores seguiram Brummit e Powell (1992). Para a classificação das famílias botânicas, foi adotado o Angiosperm Phylogeny Group III (APGIII, 2009).

Os parâmetros quantitativos estimados para a vegetação foram: riqueza florística, diversidade, densidade absoluta (DA), densidade relativa (DR), dominância absoluta (DoA), dominância relativa (DoR), frequência absoluta (FA), frequência relativa (FR) (MUELLER-DOMBOIS; ELLENBERG,1974), valor de importância (VI) e valor de cobertura (VC) (CURTIS; MCINTOSH, 1951). A diversidade florística foi avaliada pelos índices de Shannon-Wiener (H') (MAGURRAN, 1988) e de equabilidade de Pielou (J') (MITCHELL, 2007).

A suficiência amostral foi avaliada pela curva de acumulação de espécies que foi gerada aleatoriamente, com 1000 interações. Para estimar a riqueza de espécies foram utilizados dois métodos não paramétricos (COLWELL; CODDINGTON, 1994): jackknife, 1a e $2^{\mathrm{a}}$ ordens e bootstrap.

A riqueza da área de estudo foi comparada com a riqueza de outras áreas de mata ciliar (ROMAGNOLO; SOUZA, 2000; BATTILANI et al., 2005; OLIVEIRA et al., 2009; MATOS; FELFILI, 2010; RODRIGUES et al., 2010; BUENO et al., 2011) através do método de rarefação baseada em números de indivíduos com o objetivo de padronizar o esforço amostral (GOTELLI; COLWELL, 2001).

A análise de agrupamento foi efetuada a partir de uma matriz de presença/ausência dos táxons identificados ao nível específico, para verificar a similaridade florística entre a área de estudo e outras áreas de mata ciliar (ROMAGNOLO; SOUZA, 2000, BATTILANI et al., 2005, PINTO et al., 2005, OLIVEIRA et al., 2009, MATOS; FELFILI, 2010, RODRIGUES et al., 2010, BUENO et al., 2011). Nesta matriz, foi utilizado o índice de similaridade de Sørensen (Sø) e o método pareado não ponderado baseado na média aritmética de grupo - UPGMA (CHATFIELD; COLINS, 1983).

As análises e gráficos foram realizados por meio dos programas FITOPAC 2.1.2.85 (SHEPHERD, 2010) e R (R CORE TEAM, 2012).

\section{Resultados e Discussão}

A curva média de acumulação de espécies, gerada aleatoriamente a partir de várias ordenações distintas (COLEMAN, 1982), não apresentou patamar (Figura 2). Segundo Silva et al. (2008), a não estabilização da curva sugere alta riqueza específica e uma distribuição espacial das espécies restritas a pequenas porções no espaço e é um indicativo de que o esforço amostral deve ser aumentado. Os valores estimados de diversidade pelo método de jackknife de $1^{\mathrm{a}}$ e $2^{\mathrm{a}}$ ordens indicaram que $72 \%$ e $65 \%$ das espécies, respectivamente, foram amostradas. Pelo método de bootstrap foram amostradas $84 \%$ das espécies. 
No levantamento florístico foram amostradas 105 espécies distribuídas em 87 gêneros e 42 famílias, sendo o hábito predominante o arbóreo (Tabela 1). As dez famílias que contribuíram com a maior riqueza, representando $60 \%$ das espécies encontradas, foram: Fabaceae, com 26 espécies (25\%), seguida por Apocynaceae com seis (6\%), Malvaceae e Bignoniaceae com cinco (5\%) cada, Annonaceae, Myrtaceae e Rubiaceae com quatro (4\%) cada, e Malpighiaceae, Moraceae e Sapindaceae, com três (3\%) cada.

No levantamento estrutural foram amostrados 217 indivíduos, distribuídos em 54 espécies, 49 gêneros e 29 famílias (Tabela 2). A altura máxima das espécies foi de $20,0 \mathrm{~m}$ e a altura mínima 2,0 m, sendo o diâmetro máximo de $57,30 \mathrm{~cm}$.
FIGURA 2: Curva de acumulação de espécies de um trecho de mata ciliar do rio Carinhanha. A região sombreada representa o intervalo de confiança de $95 \%$ ao redor dos valores estimados. A linha horizontal mais grossa representa a mediana, a caixa o intervalo interquatil e as linhas tracejadas, os valores extremos.

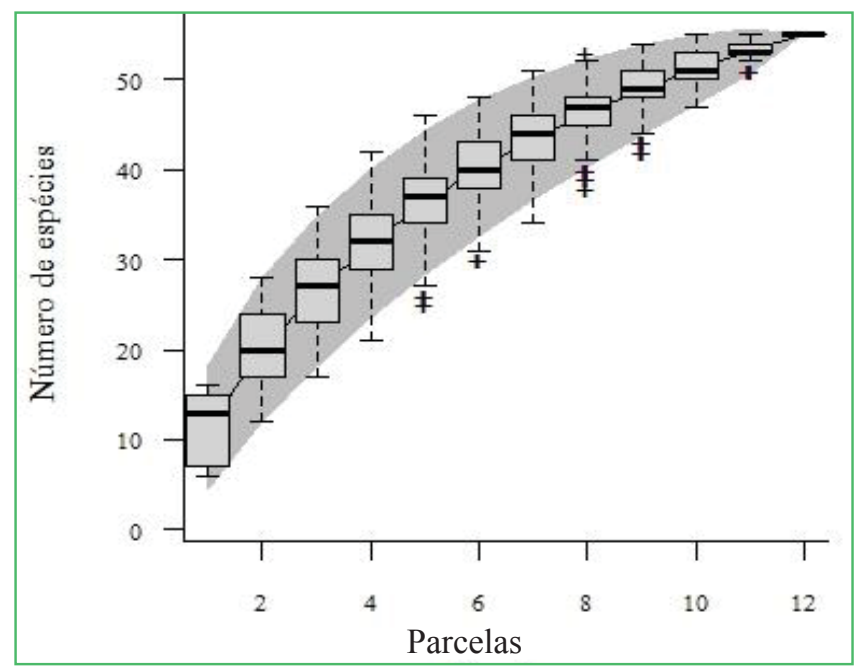

TABELA 1: Relação das espécies ocorrentes em trecho de mata ciliar do rio Carinhanha, Feira da Mata, Bahia, com seus respectivos hábitos e nomes populares.

\begin{tabular}{|c|c|c|c|c|}
\hline Famílias/espécies & Nome popular & Hábito & $\begin{array}{c}\text { Voucher } \\
\text { Guedes, M. L. } \\
\text { et al. }\end{array}$ & № ALCB \\
\hline \multicolumn{5}{|l|}{ AMARANTHACEAE } \\
\hline $\begin{array}{l}\text { Alternanthera brasiliana (L.) Kuntze } \\
\text { ANACARDIACEAE }\end{array}$ & & herbáceo & 13304 & 78342 \\
\hline $\begin{array}{l}\text { Astronium fraxinifolium } \text { Schott } \\
\text { ANNONACEAE }\end{array}$ & gonçalo-alves & árvore & 13479 & 78568 \\
\hline Annona coriacea Mart. & araticum & árvore & 13400 & 78677 \\
\hline Annona leptopetala (R.E.Fr.) H.Rainer & & árvore & 13528 & 78618 \\
\hline Annona tomentosa R.E.Fr. & araticum & árvore & 13386 & 78473 \\
\hline $\begin{array}{l}\text { Oxandra reticulata Maas } \\
\text { APOCYNACEAE }\end{array}$ & atinha & árvore & 13300 & 78338 \\
\hline Allamanda puberula A.DC. & leiteira & arbusto & 13335 & 78373 \\
\hline Aspidosperma macrocarpon Mart. & pereiro & árvore & 13417 & 78505 \\
\hline Aspidosperma parvifolium A.DC. & amarelão & árvore & 13325 & 78363 \\
\hline Aspidosperma tomentosum Mart. & pereiro-do-campo & árvore & 13364 & 78406 \\
\hline Hancornia speciosa Gomes & mangaba & árvore & 13385 & 78472 \\
\hline $\begin{array}{l}\text { Himatanthus drasticus (Mart.) Plumel } \\
\text { BIGNONIACEAE }\end{array}$ & janaúba & árvore & 13388 & 78475 \\
\hline Cuspidaria sceptrum (Cham.) L.G.Lohmann & lírio-do-campo & liana & 13379 & 78466 \\
\hline Handroanthus ochraceus (Cham.) Mattos & pau-d'arco & árvore & 13396 & 78483 \\
\hline
\end{tabular}




\begin{tabular}{|c|c|c|c|c|}
\hline Famílias/espécies & Nome popular & Hábito & $\begin{array}{l}\text { Voucher } \\
\text { Guedes, M. L. } \\
\text { et al. }\end{array}$ & № ALCB \\
\hline $\begin{array}{l}\text { Handroanthus serratifolius (A.H.Gentry) } \\
\text { S.Grose }\end{array}$ & $\begin{array}{l}\text { ipê-amarelo, ipê- } \\
\text { do-cerrado }\end{array}$ & árvore & $\mathrm{s} / \mathrm{n}$ & $\mathrm{s} / \mathrm{n}$ \\
\hline Jacaranda mimosifolia D.Don. & jacarandá-mimoso & árvore & 13371 & 78458 \\
\hline $\begin{array}{l}\text { Zeyheria montana Mart. } \\
\text { BORAGINACEAE }\end{array}$ & bolsa-de-pastor & árvore & 13428 & 78516 \\
\hline Cordia glabrata (Mart.) A.DC. & $\begin{array}{l}\text { louro-preto, louro- } \\
\text { branco }\end{array}$ & árvore & 13359 & 78398 \\
\hline $\begin{array}{l}\text { Cordia trichotoma (Vell.) Arráb. ex Steud. } \\
\text { CACTACEAE }\end{array}$ & freijó & árvore & 13463 & 78551 \\
\hline $\begin{array}{l}\text { Tacinga inamoena (K.Schum.) N.P.Taylor \& } \\
\text { Stuppy } \\
\text { CALOPHYLLACEAE }\end{array}$ & quipá & arbusto & 13342 & 78380 \\
\hline Calophyllum brasiliense Camb. & landim & árvore & 13482 & 78571 \\
\hline $\begin{array}{l}\text { Kielmeyera coriacea Mart. \& Zucc. } \\
\text { CARYOCARACEAE }\end{array}$ & pau-santo & árvore & 13403 & 78491 \\
\hline $\begin{array}{l}\text { Caryocar brasiliense Cambess. } \\
\text { CELASTRACEAE }\end{array}$ & Pequi & árvore & 13381 & 78468 \\
\hline $\begin{array}{l}\text { Maytenus gonoclada Mart. } \\
\text { CHRYSOBALANACEAE }\end{array}$ & catinga-de-porco & árvore & 13368 & 78414 \\
\hline Hirtella racemosa Lam. & azeitona-do-mato & arbusto & 13405 & 78493 \\
\hline $\begin{array}{l}\text { Licania humilis Cham. \& Schltdl. } \\
\text { COMBRETACEAE }\end{array}$ & $\begin{array}{l}\text { marmelinho-do- } \\
\text { cerrado }\end{array}$ & árvore & 13414 & 78502 \\
\hline Combretum mellifluum Eichler & vaqueta & árvore & 13559 & 78649 \\
\hline $\begin{array}{l}\text { Terminalia fagifolia Mart. } \\
\text { CONVOLVULACEAE }\end{array}$ & pau-de-rato & árvore & 13523 & 78613 \\
\hline Bonamia burchellii (Choisy) Hallier f. & & trepadeira & 13438 & 78526 \\
\hline $\begin{array}{l}\text { Jacquemontia evolvuloides (Moric.) Meisn. } \\
\text { CYPERACEAE }\end{array}$ & estrelinha-azul & herbáceo & 13355 & 78393 \\
\hline $\begin{array}{l}\text { Bulbostylis scabra (J.Presl \& C.Presl.) } \\
\text { C.B.Clarke } \\
\text { DILLENIACEAE }\end{array}$ & & herbáceo & 13395 & 78482 \\
\hline $\begin{array}{l}\text { Curatella americana L. } \\
\text { ERYTHROXYLACEAE }\end{array}$ & lixeira & árvore & 13338 & 78376 \\
\hline $\begin{array}{l}\text { Erythroxylum subrotundum A.St.-Hil. } \\
\text { EUPHORBIACEAE }\end{array}$ & & arbusto & 13320 & 78358 \\
\hline Croton campestris A.St.-Hil. & velame & arbusto & 13343 & 78381 \\
\hline $\begin{array}{l}\text { Manihot jacobinensis Müll.Arg. } \\
\text { FABACEAE }\end{array}$ & maniçoba & árvore & 13344 & 78382 \\
\hline Aeschynomene histrix Poir. & lentilha-do-campo & herbáceo & 13373 & 78460 \\
\hline Anadenanthera colubrina (Vell.) Brenan & angico & árvore & 13310 & 78348 \\
\hline Andira vermifuga (Mart.) Benth. & amargoso & árvore & 13322 & 78360 \\
\hline Bionia coriacea (Nees \& Mart.) Benth. & & sub-arbusto & 13410 & 78498 \\
\hline Bowdichia virgilioides Kunth & sucupira & árvore & 13415 & 78503 \\
\hline Calliandra dysantha Benth. & quebra-foice & arbusto & 13358 & 78397 \\
\hline Centrolobium sclerophyllum H.C.Lima & putumujú & árvore & 13360 & 78399 \\
\hline Copaifera langsdorffii Desf. & copaíba & árvore & 13464 & 78552 \\
\hline Dimorphandra mollis Benth. & fava-d'anta & árvore & 13454 & 78542 \\
\hline Hymenaea stigonocarpa Mart. ex Hayne & jatobá & árvore & 13391 & 78478 \\
\hline
\end{tabular}




\begin{tabular}{|c|c|c|c|c|}
\hline Famílias/espécies & Nome popular & Hábito & $\begin{array}{c}\text { Voucher } \\
\text { Guedes, M. L. } \\
\text { et al. }\end{array}$ & № ALCB \\
\hline Inga laurina (Sw.) Willd. & ingá & árvore & 13334 & 78372 \\
\hline Inga vera Willd. & ingá & árvore & 13577 & 78667 \\
\hline Leptolobium dasycarpum Vogel & perobinha & árvore & 13666 & 80128 \\
\hline Machaerium aculeatum Raddi & $\begin{array}{l}\text { jacarandá-de- } \\
\text { espinho }\end{array}$ & árvore & 13431 & 78519 \\
\hline Machaerium opacum Vogel & jacarandá-da-Bahia & árvore & 13314 & 78352 \\
\hline Plathymenia reticulata Benth. & vinhático & árvore & 13365 & 78407 \\
\hline Poecilanthe subcordata Benth. & coração-de-negro & árvore & 13462 & 78550 \\
\hline Poeppigea procera C. Presl. & lava-cabelo & árvore & 13460 & 78548 \\
\hline Pterodon emarginatus Vogel & sucupira-branca & árvore & 13477 & 78566 \\
\hline $\begin{array}{l}\text { Senna macranthera (DC. ex Collad.) H.S.Irwin } \\
\& \text { Brneby }\end{array}$ & fedegoso & árvore & 13426 & 78514 \\
\hline Senna silvestris (Vell.) H.S.Irwin \& Barneby & são-joão & arbusto & 13401 & 78489 \\
\hline $\begin{array}{l}\text { Senna spectabilis (DC.) H.S.Irwin \& Barneby } \\
\text { var. excelsa (Schrad.) H.S.Irwin \& Barneby }\end{array}$ & canafístula & arbusto & 13588 & 78678 \\
\hline Senna splendida (Vogel) H.S.Irwin \& Barneby & fedegoso & arbusto & 13394 & 78481 \\
\hline Stylosanthes capitata Vogel & & herbáceo & 13380 & 78467 \\
\hline Trischidium molle (Benth.) H.E.Ireland & brinquinho & arbusto & 13303 & 78341 \\
\hline $\begin{array}{l}\text { Vatairea macrocarpa (Benth.) Ducke } \\
\text { KRAMERIACEAE }\end{array}$ & amargoso & árvore & 13347 & 78385 \\
\hline $\begin{array}{l}\text { Krameria argentea Mart. ex Spreng. } \\
\text { LAURACEAE }\end{array}$ & ratinha-da-terra & herbáceo & 13308 & 78346 \\
\hline $\begin{array}{l}\text { Aniba sp. } \\
\text { LORANTHACEAE }\end{array}$ & & árvore & 13423 & 78511 \\
\hline Struthanthus syringifolius (Mart.) Mart. & erva-de-passarinho & $\begin{array}{l}\text { hemiepífita } \\
\text { arbustiva }\end{array}$ & 13413 & 78501 \\
\hline LYTHRACEAE & & & & \\
\hline $\begin{array}{l}\text { Lafoensia pacari A.St.-Hil. } \\
\text { MALPIGHIACEAE }\end{array}$ & dedaleiro & árvore & 13321 & 78359 \\
\hline Banisteriopsis malifolia (Nees \& Mart.) B.Gates & cipó-prata & liana & 13409 & 78497 \\
\hline Banisteriopsis stellaris (Griseb.) B.Gates & & liana & 13329 & 78367 \\
\hline $\begin{array}{l}\text { Byrsonima vacciniifolia A.Juss. } \\
\text { MALVACEAE }\end{array}$ & murici & árvore & 13309 & 78347 \\
\hline Luehea grandiflora Mart. \& Zucc. & açoita-cavalo & árvore & 13383 & 78470 \\
\hline Pavonia garckeana Gürke & & herbáceo & 13357 & 78396 \\
\hline $\begin{array}{l}\text { Pseudobombax tomentosum (Mart. \& Zucc.) } \\
\text { Arobyns }\end{array}$ & embiruçu & árvore & 13469 & 78558 \\
\hline Sida angustissima A.St.-Hil. & vassourinha & herbáceo & 13307 & 78345 \\
\hline $\begin{array}{l}\text { Waltheria ferruginea A.St.-Hil. } \\
\text { MELASTOMATACEAE }\end{array}$ & & arbusto & 13341 & 78379 \\
\hline $\begin{array}{l}\text { Miconia prasina (Sw.) DC. } \\
\text { MORACEAE }\end{array}$ & mundururu & árvore & 13376 & 78463 \\
\hline Brosimum gaudichaudii Trécul & inharé & árvore & 13556 & 78646 \\
\hline Ficus obtusifolia Kunth & figueira & árvore & 13375 & 78462 \\
\hline $\begin{array}{l}\text { Ficus obtusiuscula (Miq.) Miq. } \\
\text { MYRTACEAE }\end{array}$ & gameleira & árvore & 13461 & 78549 \\
\hline Eugenia dysenterica DC. & cagaita & árvore & 13339 & 78377 \\
\hline Eugenia punicifolia (Kunth) DC. & murta & árvore & 13389 & 78476 \\
\hline Eugenia sp. & & árvore & 13305 & 78343 \\
\hline
\end{tabular}




\begin{tabular}{|c|c|c|c|c|}
\hline Famílias/espécies & Nome popular & Hábito & $\begin{array}{c}\text { Voucher } \\
\text { Guedes, M. L. } \\
\text { et al. }\end{array}$ & № ALCB \\
\hline $\begin{array}{l}\text { Myrcia guianensis (Aubl.) DC. } \\
\text { NYCTAGINACEAE }\end{array}$ & guamirim & arbusto & 13323 & 78361 \\
\hline $\begin{array}{l}\text { Guapira opposita (Vell.) Reitz } \\
\text { OCHNACEAE }\end{array}$ & joão-mole & árvore & 13362 & 78401 \\
\hline Ouratea bahiensis Sastre & & árvore & 13553 & 78643 \\
\hline $\begin{array}{l}\text { Ouratea parvifolia (A.St.-Hil.) Engl. } \\
\text { OPILIACEAE }\end{array}$ & & árvore & 13366 & 78409 \\
\hline $\begin{array}{l}\text { Agonandra brasiliensis Miers ex Benth. \& } \\
\text { Hook.f. } \\
\text { PLUMBAGINACEAE }\end{array}$ & cereja-de-pobre & árvore & 13384 & 78471 \\
\hline Plumbago scandens $\mathrm{L}$. & caapomonga & $\begin{array}{l}\text { arbusto } \\
\text { escandente }\end{array}$ & 13411 & 78499 \\
\hline POACEAE & & & & \\
\hline $\begin{array}{l}\text { Aristida longifolia Trin. } \\
\text { Gymnopogon foliosus (Willd.) Nees } \\
\text { PROTEACEAE }\end{array}$ & barba-de-bode & $\begin{array}{l}\text { herbáceo } \\
\text { herbáceo }\end{array}$ & $\begin{array}{l}13387 \\
13354\end{array}$ & $\begin{array}{l}78474 \\
78392\end{array}$ \\
\hline $\begin{array}{l}\text { Roupala montana Aubl. } \\
\text { PTERIDACEAE }\end{array}$ & carne-de-vaca & árvore & 13350 & 78388 \\
\hline $\begin{array}{l}\text { Adiantum serratodentatum Willd. } \\
\text { RUBIACEAE }\end{array}$ & quebra-pedra & herbáceo & 13372 & 78459 \\
\hline Cordiera concolor (Cham.) Kuntze & marmelinho & arbusto & 13301 & 78339 \\
\hline Genipa americana L. & jenipapo & árvore & 13480 & 78569 \\
\hline Simira glaziovii (K.Schum.) Steyerm. & quina & árvore & 13317 & 78355 \\
\hline $\begin{array}{l}\text { Tocoyena formosa (Cham. \& Schltdl.) K.Schum. } \\
\text { RUTACEAE }\end{array}$ & jenipapo-bravo & arbusto & 13315 & 78353 \\
\hline $\begin{array}{l}\text { Zanthoxylum stelligerum Turcz. } \\
\text { SAPINDACEAE }\end{array}$ & mamica-de-cadela & árvore & 13424 & 78512 \\
\hline Dilodendron bipinnatum Radlk. & farinha-seca & árvore & 13327 & 78365 \\
\hline Magonia pubescens A.St.-Hil. & tingui-do-cerrado & árvore & 13420 & 78508 \\
\hline $\begin{array}{l}\text { Serjania lethalis A.St.-Hil. } \\
\text { SAPOTACEAE }\end{array}$ & timbó-de-peixe & liana & 13336 & 78374 \\
\hline $\begin{array}{l}\text { Pouteria ramiflora (Mart.) Radlk. } \\
\text { TURNERACEAE }\end{array}$ & pitomba-de-leite & árvore & 13345 & 78383 \\
\hline $\begin{array}{l}\text { Turnera simulans Arbo } \\
\text { URTICACEAE }\end{array}$ & chanana & herbáceo & 13356 & 78394 \\
\hline $\begin{array}{l}\text { Cecropia pachystachya Trécul } \\
\text { VERBENACEAE }\end{array}$ & embaúba & árvore & 13458 & 78546 \\
\hline Lantana pohliana Schauer & camará & subarbusto & 13424 & 78515 \\
\hline $\begin{array}{l}\text { Lippia origanoides Kunth } \\
\text { VOCHYSIACEAE }\end{array}$ & alecrim-do-campo & arbusto & 13495 & 78584 \\
\hline Qualea grandiflora Mart. & pau-terra-do-campo & árvore & 13534 & 78624 \\
\hline Qualea parviflora Mart. & pau-terra & árvore & 13532 & 78622 \\
\hline
\end{tabular}


TABELA 2: Parâmetros fitossociológicos para um trecho de mata ciliar do rio Carinhanha, Feira da Mata, Bahia. 2008. N = número de indivíduos; $\mathrm{UA}=$ unidade amostral (parcela); $\mathrm{DA}=$ densidade absoluta; $\mathrm{DR}=$ densidade relativa; $\mathrm{FA}=$ frequência absoluta; $\mathrm{FR}=$ frequência relativa; DoA = dominância absoluta; DoR = dominância relativa; $\mathrm{VI}=$ valor de importância; $\mathrm{VC}=$ valor de cobertura. Os parâmetros fitossociológicos estão dispostos em ordem decrescente de VI. Intervalo de confiança para Densidade: $\mathrm{CI}=\mathrm{P}[723 \pm 159]=0.95$.

\begin{tabular}{|c|c|c|c|c|c|c|c|c|c|c|}
\hline Espécies & $\mathbf{N}$ & UA & DA & DR & FA & FR & DoA & DoR & VI & $\mathrm{VC}$ \\
\hline Oxandra reticulata $(*)$ & 18 & 7 & 60,00 & 8,29 & 58,33 & 5,15 & 1,03 & 7,08 & 20,52 & 15,37 \\
\hline Hymenaea stigonocarpa & 20 & 6 & 66,67 & 9,22 & 50,00 & 4,41 & 0,75 & 5,13 & 18,76 & 14,35 \\
\hline Aspidosperma macrocarpon & 12 & 8 & 40,00 & 5,53 & 66,67 & 5,88 & 0,37 & 2,55 & 13,96 & 8,08 \\
\hline Terminalia fagifolia & 7 & 5 & 23,33 & 3,23 & 41,67 & 3,68 & 1,02 & 7,04 & 13,94 & 10,26 \\
\hline Copaifera langsdorffii & 3 & 3 & 10,00 & 1,38 & 25,00 & 2,21 & 1,23 & 8,45 & 12,04 & 9,83 \\
\hline Morto & 11 & 5 & 36,67 & 5,07 & 41,67 & 3,68 & 0,41 & 2,83 & 11,57 & 7,90 \\
\hline Licania humilis & 4 & 1 & 13,33 & 1,84 & 8,33 & 0,74 & 1,27 & 8,78 & 11,36 & 10,62 \\
\hline Dimorphandra mollis & 8 & 5 & 26,67 & 3,69 & 41,67 & 3,68 & 0,52 & 3,57 & 10,93 & 7,25 \\
\hline Agonandra brasiliensis & 13 & 5 & 43,33 & 5,99 & 41,67 & 3,68 & 0,18 & 1,22 & 10,89 & 7,21 \\
\hline Astronium fraxinifolium & 7 & 6 & 23,33 & 3,23 & 50,00 & 4,41 & 0,42 & 2,90 & 10,54 & 6,12 \\
\hline Caryocar brasiliense & 2 & 2 & 6,67 & 0,92 & 16,67 & 1,47 & 1,18 & 8,13 & 10,52 & 9,05 \\
\hline Machaerium орасит & 6 & 6 & 20,00 & 2,76 & 50,00 & 4,41 & 0,20 & 1,37 & 8,55 & 4,14 \\
\hline Poeppigea procera $(*)$ & 6 & 3 & 20,00 & 2,76 & 25,00 & 2,21 & 0,42 & 2,88 & 7,85 & 5,65 \\
\hline Curatella americana & 4 & 3 & 13,33 & 1,84 & 25,00 & 2,21 & 0,54 & 3,71 & 7,76 & 5,56 \\
\hline Aniba sp. & 5 & 4 & 16,67 & 2,30 & 33,33 & 2,94 & 0,30 & 2,07 & 7,32 & 4,37 \\
\hline Qualea grandiflora & 6 & 3 & 20,00 & 2,76 & 25,00 & 2,21 & 0,26 & 1,76 & 6,73 & 4,52 \\
\hline Anadenanthera colubrina & 7 & 3 & 23,33 & 3,23 & 25,00 & 2,21 & 0,19 & 1,29 & 6,72 & 4,51 \\
\hline Eugenia dysenterica & 5 & 4 & 16,67 & 2,30 & 33,33 & 2,94 & 0,17 & 1,18 & 6,43 & 3,49 \\
\hline Calophyllum brasiliense & 1 & 1 & 3,33 & 0,46 & 8,33 & 0,74 & 0,65 & 4,47 & 5,67 & 4,94 \\
\hline Magonia pubescens & 3 & 2 & 10,00 & 1,38 & 16,67 & 1,47 & 0,36 & 2,50 & 5,35 & 3,88 \\
\hline Cordia glabrata & 4 & 3 & 13,33 & 1,84 & 25,00 & 2,21 & 0,07 & 0,48 & 4,53 & 2,32 \\
\hline Handroanthus serratifolius $(*)$ & 4 & 3 & 13,33 & 1,84 & 25,00 & 2,21 & 0,06 & 0,41 & 4,46 & 2,25 \\
\hline Vatairea macrocarpa & 3 & 3 & 10,00 & 1,38 & 25,00 & 2,21 & 0,08 & 0,54 & 4,13 & 1,93 \\
\hline Maytenus gonoclada & 3 & 2 & 10,00 & 1,38 & 16,67 & 1,47 & 0,18 & 1,21 & 4,06 & 2,59 \\
\hline Ficus obtusiuscula $(*)$ & 1 & 1 & 3,33 & 0,46 & 8,33 & 0,74 & 0,39 & 2,71 & 3,91 & 3,17 \\
\hline Bowdichia virgilioides & 3 & 3 & 10,00 & 1,38 & 25,00 & 2,21 & 0,04 & 0,30 & 3,88 & 1,68 \\
\hline Myrcia guianensis & 4 & 2 & 13,33 & 1,84 & 16,67 & 1,47 & 0,07 & 0,51 & 3,82 & 2,35 \\
\hline Annona leptopetala (*) & 4 & 2 & 13,33 & 1,84 & 16,67 & 1,47 & 0,06 & 0,39 & 3,70 & 2,23 \\
\hline Pouteria ramiflora & 2 & 2 & 6,67 & 0,92 & 16,67 & 1,47 & 0,19 & 1,30 & 3,69 & 2,22 \\
\hline Luehea grandiflora & 1 & 1 & 3,33 & 0,46 & 8,33 & 0,74 & 0,36 & 2,48 & 3,67 & 2,94 \\
\hline Cecropia pachystachya & 2 & 1 & 6,67 & 0,92 & 8,33 & 0,74 & 0,26 & 1,78 & 3,44 & 2,70 \\
\hline Guapira opposita & 3 & 2 & 10,00 & 1,38 & 16,67 & 1,47 & 0,05 & 0,35 & 3,20 & 1,73 \\
\hline Brosimum gaudichaudii & 3 & 2 & 10,00 & 1,38 & 16,67 & 1,47 & 0,04 & 0,31 & 3,16 & 1,69 \\
\hline Lafoensia pacari & 2 & 2 & 6,67 & 0,92 & 16,67 & 1,47 & 0,11 & 0,72 & 3,12 & 1,65 \\
\hline Genipa americana & 1 & 1 & 3,33 & 0,46 & 8,33 & 0,74 & 0,28 & 1,90 & 3,10 & 2,36 \\
\hline Kielmeyera coriacea $(*)$ & 2 & 2 & 6,67 & 0,92 & 16,67 & 1,47 & 0,09 & 0,59 & 2,98 & 1,51 \\
\hline Jacaranda mimosifolia $(*)$ & 1 & 1 & 3,33 & 0,46 & 8,33 & 0,74 & 0,26 & 1,77 & 2,97 & 2,23 \\
\hline Centrolobium sclerophyllum(*) & 2 & 2 & 6,67 & 0,92 & 16,67 & 1,47 & 0,04 & 0,28 & 2,68 & 1,21 \\
\hline Roupala montana & 2 & 2 & 6,67 & 0,92 & 16,67 & 1,47 & 0,04 & 0,24 & 2,64 & 1,17 \\
\hline Annona coriacea & 2 & 2 & 6,67 & 0,92 & 16,67 & 1,47 & 0,02 & 0,14 & 2,53 & 1,06 \\
\hline Andira vermifuga $(*)$ & 2 & 1 & 6,67 & 0,92 & 8,33 & 0,74 & 0,07 & 0,48 & 2,14 & 1,40 \\
\hline Manihot jacobinensis(*) & 2 & 1 & 6,67 & 0,92 & 8,33 & 0,74 & 0,05 & 0,34 & 2,00 & 1,27 \\
\hline Dilodendron bipinnatum & 2 & 1 & 6,67 & 0,92 & 8,33 & 0,74 & 0,04 & 0,28 & 1,94 & 1,20 \\
\hline Senna silvestris & 2 & 1 & 6,67 & 0,92 & 8,33 & 0,74 & 0,03 & 0,19 & 1,84 & 1,11 \\
\hline Aspidosperma tomentosum & 2 & 1 & 6,67 & 0,92 & 8,33 & 0,74 & 0,02 & 0,15 & 1,80 & 1,07 \\
\hline
\end{tabular}




\begin{tabular}{lcccccccccc}
\hline Espécies & N & UA & DA & DR & FA & FR & DoA & DoR & VI & VC \\
\hline Pterodon emarginatus & 1 & 1 & 3,33 & 0,46 & 8,33 & 0,74 & 0,04 & 0,26 & 1,46 & 0,72 \\
Hirtella racemosa & 1 & 1 & 3,33 & 0,46 & 8,33 & 0,74 & 0,04 & 0,24 & 1,44 & 0,70 \\
Eugenia punicifolia & 1 & 1 & 3,33 & 0,46 & 8,33 & 0,74 & 0,02 & 0,12 & 1,32 & 0,58 \\
Zanthoxylum stelligerum $(*)$ & 1 & 1 & 3,33 & 0,46 & 8,33 & 0,74 & 0,02 & 0,11 & 1,31 & 0,57 \\
Ouratea bahiensis $(*)$ & 1 & 1 & 3,33 & 0,46 & 8,33 & 0,74 & 0,02 & 0,11 & 1,30 & 0,57 \\
Hancornia speciosa & 1 & 1 & 3,33 & 0,46 & 8,33 & 0,74 & 0,02 & 0,11 & 1,30 & 0,57 \\
Qualea parviflora & 1 & 1 & 3,33 & 0,46 & 8,33 & 0,74 & 0,01 & 0,09 & 1,29 & 0,55 \\
Handroanthus ochraceus $(*)$ & 1 & 1 & 3,33 & 0,46 & 8,33 & 0,74 & 0,01 & 0,08 & 1,28 & 0,55 \\
Leptolobium dasycarpum & 1 & 1 & 3,33 & 0,46 & 8,33 & 0,74 & 0,01 & 0,07 & 1,27 & 0,53 \\
Byrsonima vacciniifolia & 1 & 1 & 3,33 & 0,46 & 8,33 & 0,74 & 0,01 & 0,06 & 1,26 & 0,52 \\
\hline
\end{tabular}

* Espécies que não foram citadas por Ratter et al. (2003) na lista das espécies arbóreas das fisionomias savânicas do Cerrado.

A densidade encontrada foi de 723 indivíduos.ha ${ }^{-1}$ e a área basal, de $14,52 \mathrm{~m}^{2} \cdot \mathrm{ha}^{-1}$. Outros trabalhos que avaliaram trechos semelhantes de vegetação, com o mesmo critério de inclusão adotado no presente estudo, encontraram maior densidade e área basal (MATOS; FELFILI, 2010; RODRIGUES et al., 2010). Essas diferenças parecem estar relacionadas a uma maior pressão antrópica na área do presente estudo, além de diferenças em fatores bióticos e abióticos.

O valor do índice de diversidade de ShannonWiener (H') para este estudo foi de 3,62 nats.ind ${ }^{-1}$ e o índice de equabilidade de Pielou (J'), de 0,90, sendo este último considerado alto pelos critérios de Battilani et al. (2005). Assim, pode-se considerar que as espécies ocorrentes nessa mata apresentaram distribuição quase homogênea, o que sugere estabilidade na abundância. Os valores destes índices foram similares aos encontrados para outros remanescentes de mata ciliar do Cerrado (BATTILANI et al., 2005; CARVALHO et al., 2005). Os valores do índice de diversidade de Shannon-Wiener (H') geralmente encontrados para matas de galerias e, ou, ciliares do Brasil estão entre 3,6 e 4,2 nats.ind ${ }^{-1}$ (ROMAGNOLO; SOUZA, 2000; GUARINO; WALTER, 2004), o que corrobora com o valor encontrado neste estudo. O índice de ShannonWiener foi equivalente aos encontrados em Cerrados bem conservados, em áreas de unidades de conservação, e sugerem alta riqueza de espécies e uniformidade no tamanho de suas populações (SAPORETTI JR et al., 2003; MATOS; FELFILI, 2010).

Ao comparar a riqueza de espécies de Feira da Mata com trabalhos fitossociológicos de mata ciliar das regiões do Centro Oeste, Nordeste e Sudeste (Figura 3), padronizando o critério de inclusão (DAP $\geq 5 \mathrm{~cm}$ ou PAP $\geq 15 \mathrm{~cm}$ ) e o esforço amostral (curva de rarefação), observa-se maior similaridade com os levantamentos de Minas Gerais (RODRIGUES et al., 2010) e Piauí (MATOS; FELFILI, 2010), possivelmente por apresentarem condições ambientais semelhantes.

FIGURA 3: Curvas de rarefação considerando os critérios de inclusão DAP $\geq 5 \mathrm{~cm}$ ou PAP $\geq 15 \mathrm{~cm}$. P1 - Feira da Mata, BA; P2 - Jardim, MS (BATTILANI et al., 2005); P3 - Triângulo, MG (RODRIGUES et al., 2010) e P4 - Serra do Roncador, Parque Nacional Sete Cidades, PI (MATOS; FELFILI, 2010); P5 - Pantanal de Miranda, MS (BUENO et al., 2011); P6 - Aliança, PE (OLIVEIRA et al., 2009); P8 - Taquaruçu, MS (ROMAGNOLO; SOUZA, 2000).

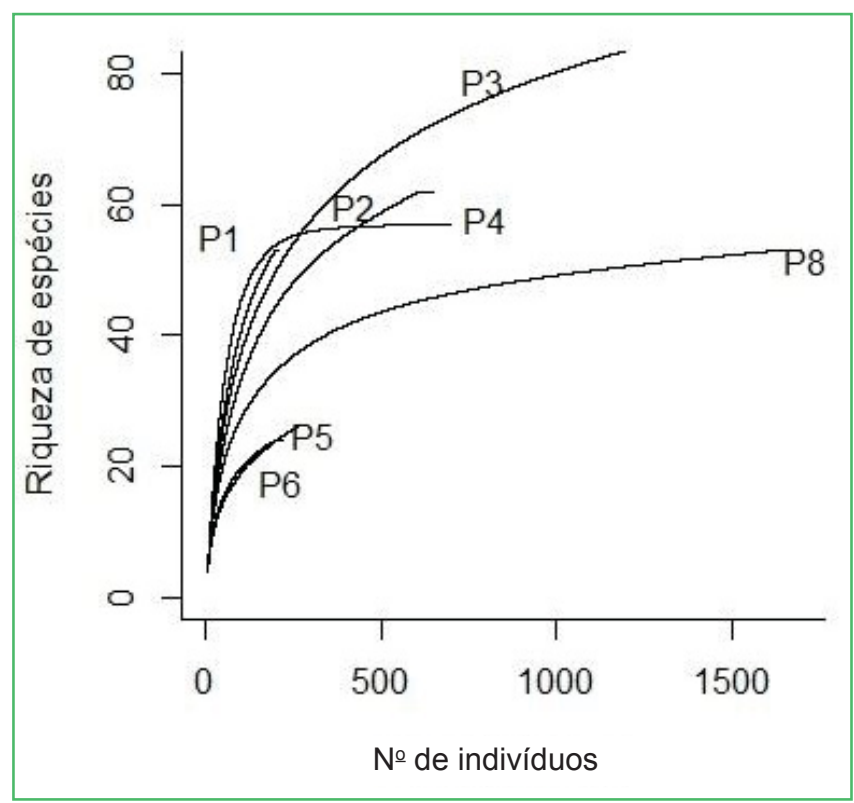


No levantamento fitossociológico, foram amostradas 54 espécies, valor que se encontrou dentro da faixa listada por Rodrigues e Nave (2001). Estes autores analisaram 43 estudos realizados em matas ciliares e verificaram que o número de espécies arbustivo-arbóreas variou entre 23 e 247 espécies. Os autores relacionaram a riqueza florística com a heterogeneidade ambiental nas áreas ciliares, que é ocupada por um mosaico de tipos vegetacionais ou mesmo por unidades fitofisionômicas distintas. Para a mata ciliar do rio Carinhanha, 10 espécies $(18,66 \%)$ foram representadas por apenas um indivíduo, e 18 (33,96\%), por dois indivíduos. Este padrão de ocupação da comunidade vegetal, caracterizado pela presença de espécies pouco abundantes e por alto percentual de espécies exclusivas, corrobora o já observado por vários autores (CARVALHO et al., 2005; MATOS; FELFILI, 2010), e é explicado por Guntzel et al. (2011), que observaram que a ocorrência de muitas espécies com baixa frequência pode estar relacionada com a heterogeneidade ambiental da área que condiciona a ocorrência de um mosaico de vegetação com diferentes tolerâncias e adaptações às condições ambientais.

As famílias que mais contribuíram com a riqueza de espécies foram Fabaceae, com 13 espécies (24,07\%), Annonaceae, Apocynaceae, Bignoniaceae e Myrtaceae, com três $(5,56 \%)$ cada. As dez famílias mais representativas em número de espécies somam cerca de $65 \%$ do total de espécies amostradas. Ressalta-se que, do total de 29 famílias, 19 (65,52\%) foram representadas por uma única espécie, refletindo a alta diversidade biológica da área. Fabaceae e Myrtaceae são citadas também como famílias mais ricas em espécies em alguns trabalhos sobre mata ciliar (ROMAGNOLO; SOUZA, 2004; CARVALHO et al., 2005; RODRIGUES et al., 2010; GÜNTZEL et al., 2011).

As famílias Fabaceae, Annonaceae, Apocynaceae e Combretaceae representaram $42,74 \%$ do valor de importância (VI), respectivamente. As três primeiras também apresentaram o maior número de indivíduos, $29,49 \%, 11,06 \%$ e $6,9 \%$, respectivamente. Isso está de acordo com o fato de que a flora lenhosa do Cerrado é composta comumente por um pequeno grupo de famílias dominantes (BRIDGEWATER et al., 2004). Os indivíduos mortos em pé ocuparam o sexto valor de
VI $(11,57)$, o que representou 5\% do total de indivíduos coletados (Tabela 2). Este valor foi equivalente ao encontrado por Matos e Felfili (2010) e pode indicar que a área não vem sofrendo grandes perturbações antrópicas ou naturais. O percentual geralmente encontrado de indivíduos mortos para as matas de galeria é em torno de 3 a $9 \%$ (FELFILI et al., 2004).

As cinco espécies com maior VI foram Oxandra reticulata, Hymenaea stigonocarpa, Aspidosperma macrocarpon, Terminalia fagifolia e Copaifera langsdorffii, representando $26,41 \%$ do VI total. De maneira geral, estas espécies apresentaram distribuição mais ampla que as demais, uma vez que tiveram densidades e frequências mais altas, exceto Copaifera langsdorffii, cujo destaque se deu em relação à área basal de apenas três indivíduos. Dentre as espécies que se destacaram em valor de importância, Astronium fraxinifolium, Caryocar brasiliense, Dimorphandra mollis e Hymenaea stigonocarpa também ocorreram em mais de 50\% das 376 áreas do bioma avaliadas por Ratter et al. (2003), confirmando a ampla distribuição destas espécies no bioma.

Do total de espécies identificadas neste trabalho para a mata ciliar do rio Carinhanha, 40 foram citadas por Ratter et al. (2003) como integrantes da lista das espécies arbóreas das fisionomias savânicas do Cerrado, com exceção de Andira vermifuga, Annona leptopetala, Centrolobium sclerophyllum, Ficus obtusiuscula, Handroanthus ochraceus, Handroanthus serratifolius, Jacaranda mimosifolia, Kielmeyera coriacea, Manihot jacobinensis, Ouratea bahiensis, Poeppigea procera, Zanthoxylum stelligerum e Oxandra reticulata, esta última tendo apresentado o maior VI (Tabela 2). Esse resultado corrobora com a afirmação de que as matas ciliares compartilham espécies com outras fitofisionomias do bioma, como florestas estacionais e cerrado sensu stricto (MATOS; FELFILI, 2010).

As espécies Anadenanthera colubrina, Astronium fraxinifolium, Cecropia pachystachya, Genipa americana, Hymenaea stigonocarpa, Machaerium aculeatum e Senna spectabilis foram encontradas também nas matas ciliares do rio Carinhanha no Norte de Minas Gerais, no domínio da Caatinga (SANTOS; VIEIRA, 2006). As espécies Calophyllum brasiliense, 
Cecropia pachystachya e Copaifera langsdorffii foram amostradas em mais de $48 \%$ e Guapira opposita em $35 \%$, dentre os 43 levantamentos florísticos e fitossociológicos de florestas ciliares do Brasil extraamazônico (RODRIGUES; NAVE, 2001). Cecropia pachystachya foi considerada uma espécie tipicamente pioneira das formações ciliares, e Copaifera langsdorffii, generalista (OLIVEIRA-FILHO; RATTER, 2001; RODRIGUES; NAVE, 2001). Terminalia fagifolia foi encontrada tanto em florestas estacionais como nos cerradões (MENDONÇA et al., 2008) e a espécie Vatairea macrocarpa foi apontada como típica da região norte-nordeste do Cerrado (FERNANDES, 2006). Portanto, as formações ciliares apresentam um conjunto de espécies típicas da unidade fitogeográfica ocorrentes no interflúvio; um conjunto de espécies de ampla distribuição; um conjunto de espécies caracterizadoras dos vários ambientes ciliares e um conjunto de espécies caracterizadoras daquela condição ecológica específica (RODRIGUES; SHEPHERD, 2001).

As espécies Licania humilis, Copaifera langsdorffii e Caryocar brasiliense responderam por $25,35 \%$ da área basal total e se destacaram entre as dez espécies mais importantes nesse parâmetro, pois os indivíduos dessas espécies apresentaram grandes diâmetros. Por outro lado, apesar da grande área basal, essas espécies apresentaram baixa densidade (apenas quatro, três e dois indivíduos, respectivamente). O pequeno número de indivíduos com diâmetros muito elevados pode ser atribuído a algum tipo de perturbação no ambiente, como a substituição da vegetação natural pela agropecuária. Contudo, são necessários estudos complementares que possam avaliar a possível interferência de fatores antrópicos na área.

A distribuição das classes diamétricas do fragmento apresenta o padrão J-invertido. Essa distribuição permite a avaliação da dinâmica do fragmento florestal, possibilitando inferir quanto ao desenvolvimento da comunidade vegetal (SIMINSKI et al. 2004). Com uma alta concentração de indivíduos nas classes de menores diâmetros percebe-se no fragmento um predomínio de indivíduos jovens; cerca de $65 \%$ dos indivíduos amostrados apresentaram diâmetro menor que $12 \mathrm{~cm}$ e cerca de $28 \%$, altura inferior a $4,6 \mathrm{~m}$. A presença de um grande número de indivíduos com diâmetro menor pode ser um indicativo de áreas que sofreram perturbações mais severas no passado, caracterizando um estágio atual de regeneração inicial (NUNES et al., 2003). Os setores que sofreram distúrbios mais leves no passado apresentaram maior densidade de árvores altas e diâmetros maiores, indicando estágio regenerativo mais avançado. Para Martins (1991) e Assunção e Felfili (2004), uma maior densidade de indivíduos menores não indica ausência de problemas de regeneração, mas sim, que a comunidade estudada pode ser autorregenerativa, caso não seja intensamente perturbada.

A composição florística da área estudada pode ser considerada distinta em relação às áreas de mata ciliar das regiões do Centro Oeste, Nordeste e Sudeste, devido aos baixos índices de similaridades obtidos (Figura 4). A área que apresentou maior semelhança com a mata ciliar deste levantamento (P1) foi a mata de galeria do Parque Nacional Sete Cidades, no Piauí (MATOS; FELFILI, 2010) (P4), com um índice de Sørensen (Sø) de 14\%, seguida por Triângulo, MG (RODRIGUES et al., 2010) (P3), com 12\%, e Jardim, MS (BATTILANI et al., 2005) (P2), com 7\%. A baixa similaridade indica uma alta heterogeneidade florística das florestas ciliares, conforme trabalhos prévios (SCARANO et al., 1997; GIEHL et al., 2011). A composição das formações ribeirinhas apresenta maior similaridade entre as áreas próximas, com histórico parecido de degradação e com condições ecológicas semelhantes, sugerindo uma heterogeneidade florística e ambiental entre áreas ciliares mais afastadas (RODRIGUES; SHEPHERD, 2001).

A área estudada compartilhou espécies com outras fisionomias do Cerrado, como florestas estacionais e cerrado sensu stricto, como também com espécies típicas da Caatinga. Percebe-se que, para este fragmento, houve influências florísticas diferenciadas que resultaram em elevada riqueza e baixa similaridade, apontando, mais uma vez, para a heterogeneidade das formações ciliares. Dessa maneira, políticas que viabilizem estratégias de conservação e recuperação de remanescentes devem ser implementadas inclusive para este fragmento, com especial atenção para espécies com alto valor para conservação biológica e para aquelas que apresentam elevado valor extrativista, como Caryocar brasiliense (pequi) e Eugenia dysenterica (cagaita). 
FIGURA 4: Dendrograma de similaridade florística entre oito levantamentos fitossociológicos de mata ciliar das regiões brasileiras do Centro Oeste, Nordeste e Sudeste: P1 - Feira da Mata, BA; P2 - Jardim, MS (BATTILANI et al., 2005); P3 - Triângulo, MG (RODRIGUES et al., 2010) e P4 - Serra do Roncador, Parque Nacional Sete Cidades, PI (MATOS; FELFILI, 2010); P5 Pantanal de Miranda, MS (BUENO et al., 2011); P6 - Aliança, PE (OLIVEIRA et al., 2009); P7 - Larvas, MG (PINTO et al., 2005); P8 - Taquaruçu, MS ( ROMAGNOLO; SOUZA, 2000).

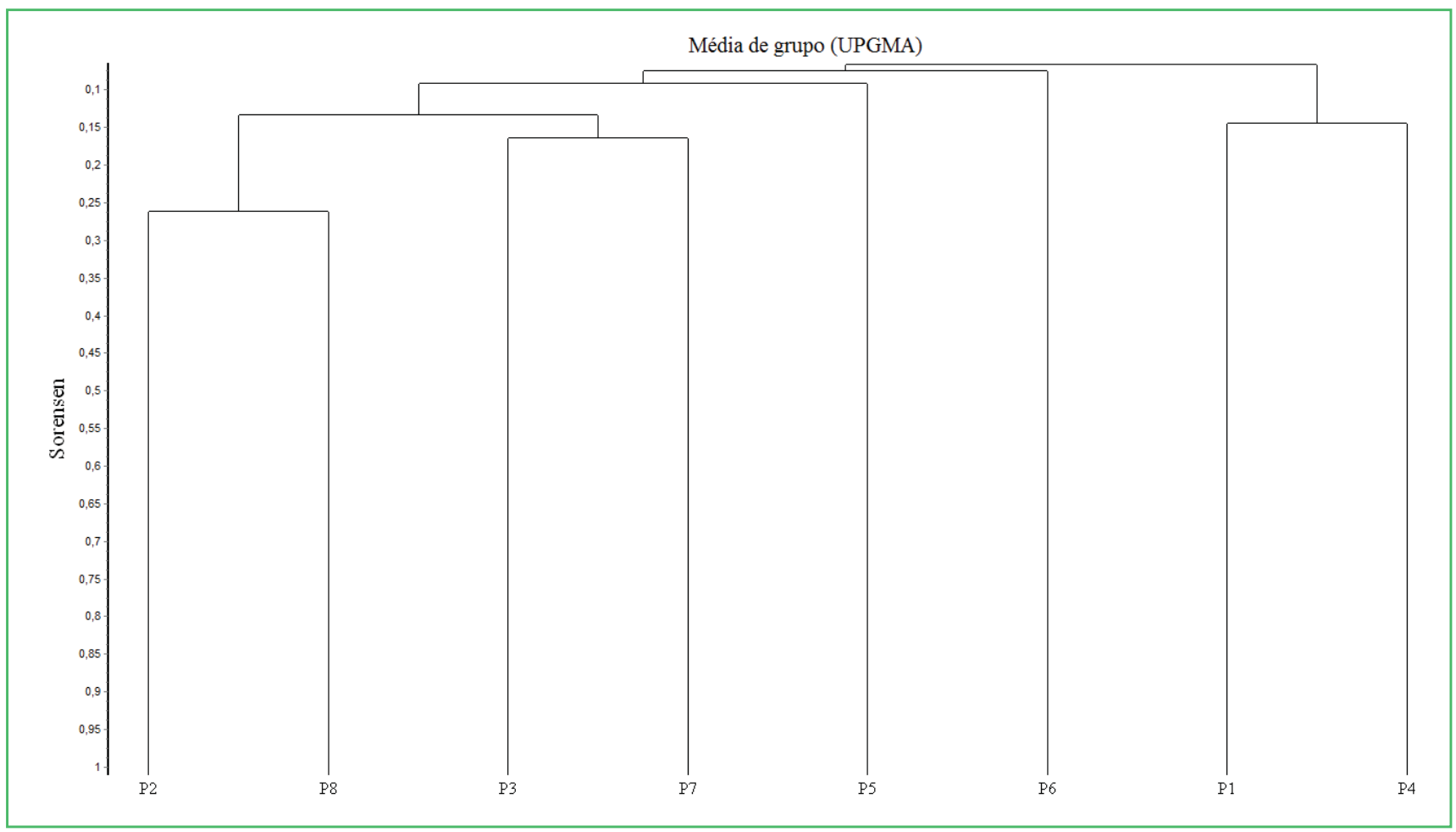

\section{Agradecimentos}

Organização das Nações Unidas para agricultura e alimentação (FAO), Ministério do Meio Ambiente, Associação plantas do Nordeste (APNE), Universidade Estadual de Feira de Santana (UEFS) e todos os participantes do projeto Fitossociologia do rio São Francisco.

\section{Referências}

ANA - AGÊNCIA NACIONAL DE ÁGUAS. Sistema de informações hidrólogicas. 2005. Disponível em: $<$ http://hidroweb. ana.gov.br/>. Acesso em: 14 fev. 2013.

APGIII - ANGIOSPERM PHYLOGENY GROUP. An update of the Angiosperm Phylogeny Group classification for the orders and families of flowering plants. Botanical Journal of the Linnean Society, Londres, v. 161, p. 105-121, 2009.

ASSUNÇÃO, S. L.; FELFILI, J. M. Fitossociologia de um fragmento de cerrado sensu stricto na APA do Paranoá, DF, Brasil. Acta Botanica Brasilica, Feira de Santana, v. 18, n. 4, p. 903-909, 2004.
BATTILANI, J. L.; SCREMIN-DIAS, E.; SOUZA, A. L. T. Fitossociologia de um trecho da mata ciliar do rio da Prata, Jardim, MS, Brasil. Acta Botanica Brasilica, Feira de Santana, v. 19, n. 3, p. 597-608, 2005.

BRIDGEWATER, S.; RATTER, J. A.; RIBEIRO, J. F. Biogeografic patterns, B-diversity and dominance in the cerrado biome of Brazil. Biodiversity and Conservation, Dordrecht, v. 13, n. 12, p. 22952318, 2004.

BRUMMIT, R. K.; POWELL, M. C. E. Authors of plants names. London: Royal Botanic Gardens Kew, 1992. 732 p.

BUENO, B.; GALETTI, V. S.; VICENTIN, W.; DAMASCENO JR., G. A.; POTT, A. Comparação de dois métodos fitossociológicos aplicados à mata ciliar do rio Miranda, Pantanal do Miranda, Corumbá, MS, Brasil. In: FELFILI, J. M.; EISENLOHR, P. V.; MELO, M. M. R. F.; ANDRADE, L. A.; MEIRA NETO, J. A. A. (Org.). Fitossociologia no Brasil: métodos e estudos de casos. Viçosa: Editora UFV, 2011. p. 337-556.

CARVALHO, D. A.; OLIVEIRA-FILHO, A. T.; VILELA, E. A.; CURI, N., VAN DEN BERG, E.; FONTES, M. A. L.; BOTEZELLI, L. Distribuição de espécies arbóreo-arbustivas ao longo de um gradiente de solos e topografia em um trecho de floresta ripária do Rio São Francisco em Três Marias, MG, Brasil. Revista Brasileira de Botânica, São Paulo, v. 28, n. 2, p. 329-345, 2005. 
CHATFIELD, C.; COLLINS, A. J. Introdution to multivariate analysis. London: Chapman and Hall, 1983. 246 p.

CBHSF. Bacia hidrográfica do Rio São Francisco. In: Comitê de Bacia Hidrográfica do Rio São Francisco. 2006. Disponível em: $<$ http://cbhsaofrancisco.org.br/>. Acesso em: 26 jul. 2011.

COLEMAN, B. D.; MARES, M. A.; WILLIG, M. R.; HSIEH, Y. Randomness, area and species richness. Ecology, New York, v. 63, p. 1121-1133, 1982.

COLWELL, R. K.; CODDINGTON, J. Estimating terrestrial biodiversity through extrapolation. Philosophical Transactions of the Royal Society of London Series B-Biological Sciences, London, v. 345, p. 101-118, 1994.

COUTINHO, L. M. O bioma do Cerrado. In: KLEIN, A. L. (Ed.). Eugen Warming e o cerrado brasileiro: um século depois. São Paulo: Editora UNESP, 2002. p. 77-91.

CURTIS, J. T.; MCINTOSH, R. P. An upland forest continuum in the Prairie-Forest border region of Wisconsin. Ecology, New York, v. 32, n. 3, p. 476-496, 1951.

EMBRAPA. O novo mapa do solo do Brasil - Legenda atualizada. 2011. Disponível em: <http://sosgisbr.com/2012/06/04/mapa-desolos-do-brasil-2011-embrapa/>. Acesso em: 9 mar. 2013.

FELFILI, J. M.; SILVA JÚNIOR, M. C. (Org.). Biogeografia do Bioma Cerrado: estudo fitofisionômico da Chapada do Espigão Mestre do São Francisco. Brasília: Universidade de Brasília, Departamento de Engenharia Florestal. 2001. 152 p.

FELFILI, J. M.; SILVA JÚNIOR, M. C.; SEVILHA, A. C.; FAGG, C. W.; WALTER, B. M. T.; NOGUEIRA, P. E.; REZENDE, A. V. Diversity, floristic and structural patterns of cerrado vegetation in Central Brazil. Plant Ecology, Dordrecht, v. 175, p. 37-46, 2004.

FERNANDES, A. Fitogeografia brasileira: províncias florísticas. Fortaleza: Realce Editora e Indústria Gráfica. 2006. 202 p.

FILGUEIRAS, T. S.; BROCHADO, A. L.; NOGUEIRA, P. E.; GUALA II, G. F. Caminhamento: um método expedito para levantamentos florísticos qualitativos. Caderno Geociências, Rio de Janeiro, v. 2, n. 4, p. 39-43, 1994.

GIEHL, E. L. H.; BUDKE, J. C.; OLIVEIRA-FILHO, A. T.; JARENKOW, J. A. Variações florestais e relações com variáveis geográficas e climáticas em florestas ribeirinhas do Sudeste da América do Sul. In: FELFILI, J. M.; EISENLOHR, P. V.; MELO, M. M. R. F.; ANDRADE, L. A.; MEIRA NETO, J. A. A. (Org.). Fitossociologia no Brasil. Métodos e estudos de casos. Viçosa: EDUFV, 2011. p. 504-519.

GOTELLI, N. J.; COLWELL, R. K. Quantifying biodiversity: procedures and pitfalls in the measurement and comparison of species richness. Ecology Letters, Montpellier, v. 4, p. 379-391, 2001.

GUARINO, E. S. G.; WALTER, B. M. T. Fitossociologia de dois trechos inundáveis de Matas de Galeria no Distrito Federal, Brasil. Acta Botanica Brasilica, Feira de Santana, v. 19, p. 431$442,2004$.

GÜNTZEL, A. M.; DIAS, N. R.; COERTJENS, C. M.; SILVA, G. C.; VIEIRA, E. A. Análise fitossociológica de um remanescente de vegetação na microbacia do Córrego Criminoso (Bacia do Rio Taquari, Coxim, MS, Brasil): subsídios para a recomposição da vegetação. Acta Botanica Brasilica, Feira de Santana, v. 25, n. 3, p. 586-592, 2011.
INMET - INSTITUTO NACIONAL DE METEOROLOGIA. Banco de dados meteorológicos para ensino e pesquisa. 2013. Disponível em: <http://www.inmet.gov.br/portal/ index. php?r=bdmep/bdmep $>$. Acesso em: 14 out. 2013.

KAGEYAMA, P.; GANDARA, F. B. Recuperação de áreas ciliares In: RODRIGUES, R. R.; LEITÃO FILHO, H. F. (Ed.). Matas ciliares: conservação e recuperação. São Paulo: EDUSP, 2001. p. 249-269.

KLINK, C. A.; MACHADO, R. B. Conservation of the Brazilian Cerrado. Conservation Biology, San Francisco, v. 19, n. 3, p. 707713, 2005.

MAGURRAN, A. E. Ecological diversity and its measurement. Londres: Croom Helm, 1988. 179 p.

MARTINS, F. R. Estrutura de uma floresta mesófila. Campinas: UNICAMP, 1991. 245 p.

MENDONÇA, R. C.; FELFILI, J. M.; WALTER, B. M. T.; SILVA JÚNIOR, M. C.; REZENDE, A. V.; FILGUEIRAS, T. S.; NOGUEIRA, P. E. Flora vascular do Cerrado. In: SANO, S. M.; ALMEIDA, S. P. (Ed.). Cerrado: ambiente e flora. Planaltina: EMBRAPA-CPAC, 2008. p. 289-556.

MATOS, M. Q.; FELFILI, J. M. Florística, fitossociologia e diversidade da vegetação arbórea nas matas de galeria do Parque Nacional de Sete Cidades (PNSC), Piauí, Brasil. Acta Botanica Brasilica, Feira de Santana, v. 24, n. 2, p. 483-496, 2010.

MITCHELL, J. Quantitative Analysis by the Point-Centered Quarter Method. 2007. Disponível em: <http://people.hws.edu/ mitchell/PCQM.pdf>. Acesso em: 16 jan. 2012.

MMA - MINISTÉRIO DO MEIO AMBIENTE. 2013. Disponível em: <http://www.mma.gov.br/ biomas/cerrado>. Acesso em: 15 jan. 2013.

MUELLER-DOMBOIS, D.; ELLENBERG, H. Aims and methods of vegetation ecology. New York: John Wiley and Sons, 1974. 547 p. MYERS, N.; MITTERMEIER, R. A.; MITTERMEIER, C. G.; FONSECA, G. A. B.; KENT, J. Biodiversity hotspots for conservation priorities. Nature, London, v. 403, p. 853-858, 2000.

NUNES, Y. R. F.; MENDONÇA, A. V. R.; BOTEZELLI, L.; MACHADO, E. L. M.; OLIVEIRA-FILHO, A. T. Variação da fisionomia, diversidade, e composição de guildas da comunidade arbórea em um fragmento de floresta estacional semidecidual em Lavras, MG. Acta Botanica Brasilica, Feira de Santana, v. 17, p. 213-229, 2003.

OLIVEIRA, E. B.; MARANGON, L. C.; FELICIANO, A. L. P.; FERREIRA, R. L. C.; RÊGO, P. L. Estrutura fitossociológica de um fragmento de mata ciliar, Rio Capibaribe Mirim, Aliança, Pernambuco. Revista Brasileira de Ciências Agrárias, Recife, v. 4, n. 2, p. 167-172, 2009.

OLIVEIRA-FILHO, A. T.; RATTER J. A. Padrões florísticos das matas ciliares da região do cerrado e a evolução das paisagens do Brasil central durante o quartenário tardio. In: RODRIGUES, R. R.; LEITÃO FILHO, H. F. (Ed.). Mata ciliares: conservação e recuperação. São Paulo: EDUSP, 2001. p. 73-89.

PAGOTTO, T. C. S.; CAMILOTTI, D. C.; LONGO, J. M.; SOUZA, P. R. Bioma Cerrado. In: PAGOTTO, T. C.; SOUZA, P. R. (Org.). Biodiversidade do complexo Aporé-Sucuriú: subsídios à conservação manejo do bioma Cerrado. Campo Grande: UFMS, 2006. p. 18-30. 
PINTO, L. V. A.; DAVIDE, A. C.; BOTELHO, S. A.; OLIVEIRAFILHO, A. T. Distribuição das espécies arbóreo-arbustivas ao longo do gradiente de umidade do solo de nascentes pontuais da bacia hidrográfica do Ribeirão Santa Cruz, Lavras, MG. Cerne, Lavras, v. 11, n. 3, p. 294-305, 2005.

RATTER, J. A.; BRIDGEWATER, S.; ATKINSON, R.; RIBEIRO, J. F. Analysis of the floristic composition of the Brazilian cerrado vegetation III:Comparison of the vegetation of 376 areas. Edinburgh Journal of Botany, Edinburgh, v. 60, n. 1, p. 57-109, 2003.

R CORE TEAM. R: A language and environment for statistical computing. Vienna: R Foundation for Statistical Computing, 2012. Disponível em: <http://www.R-project.org/>.

RIBEIRO, J. F.; WALTER, B. M. T. As principais fitofisionomias do Bioma Cerrado. In: SANO, S. M.; ALMEIDA, S. P.; RIBEIRO, J. F. (Ed.). Ecologia e flora. Vol. 1. Brasília: EMBRAPA, 2008. p. 152-212.

RODRIGUES, R. R.; NAVE, A. G. Heterogeneidade florística das matas ciliares. In: RODRIGUES, R. R.; LEITÃO FILHO, H. F. (Ed.). Matas ciliares: conservação e recuperação. São Paulo: EDUSP, 2001. p. 45-71.

RODRIGUES, R. R.; SHEPHERED, G. J. Recuperação de áreas ciliares. In: RODRIGUES, R. R.; LEITÃO FILHO, H. F. (Ed.). Matas ciliares: conservação e recuperação. São Paulo: EDUSP, 2001. p. 101-107.

RODRIGUES, V. H. P.; LOPES, S. F.; ARAÚJO, G. M. E; SCHIAVINI, I. Composição, estrutura e aspectos ecológicos da floresta ciliar do rio Araguari no Triângulo Mineiro. Hoehnea, São Paulo, v. 37, n. 1, p. 87-105, 2010.

ROMAGNOLO, M. B.; SOUZA, M. C. Análise florística e estrutural de florestas ripárias do Alto Rio Paraná, Taquaruçu, MS. Acta Botanica Brasilica, Feira de Santana, v. 14, p. 163-174, 2000. ROMAGNOLO, M. B.; SOUZA, M. C. Os gêneros Calycorectes O. Berg, Hexachlamys O. Berg, Myrcianthes O. Berg, Myrciaria O. Berg e Plinia L. (Myrtaceae) na planície alagável do alto rio Paraná, Brasil. Acta Botanica Brasilica, Feira de Santana, v. 18, n. 3, p. 613-627, 2004.

SANTOS, R. M.; VIEIRA, F. A. Estrutura e florística de um trecho de mata ciliar do rio Carinhanha no extremo norte de Minas Gerais, Brasil. Revista Científica Eletrônica de Engenharia Florestal, Graça, n. 5, p. 1-5, 2005.
SANTOS, R. M.; VIEIRA, F. A. Floristica e estrutura da comunidade arbórea de fragmentos de matas ciliares dos rios São Francisco, Cochá e Carinhanha, Norte de Minas Gerais, Brasil. Revista Científica Eletrônica de Engenharia Florestal, Graça, n. 8, 1-30, 2006.

SAPORETTI JR, A. W.; MEIRA NETO, J. A. A.; ALMADO, R. P. Fitossociologia de cerrado sensu stricto, Abaeté-MG. Revista Árvore, Viçosa, v. 27, n. 3, p. 413-419, 2003.

SARMENTO, T. R.; SILVA JÚNIOR, M. C. Composição florística e fitossociologia das comunidades lenhosas do Cerrado sentido restrito em duas posições topográficas no Jardim Botânico de Brasília, DF. Boletim Herbário Ezechias Paulo Heringer, Brasília, v. 17, p. 79-92, 2006.

SCARANO, F. R.; RIBEIRO, K. T.; MORAES L. F. D.; LIMA, H. C. Plant establishment on flooded and unflooded patches of a freshwater swamp forest in southeastern Brazil. Journal of Tropical Ecology, Cambridge, v. 13, p. 793-803, 1997.

SHEPHERD, G. J. Fitopac 2.1.2.85. Manual do usuário. Campinas: Departamento de Botânica, Universidade Estadual de Campinas, Campinas. 2010.

SILVA, H. G.; FIGUEIREDO, N.; ANDRADE, G. V. Estrutura da vegetação de um cerradão e a heterogeneidade regional do cerrado no Maranhão, Brasil. Revista Árvore, Viçosa, v. 32, n. 5, p. 921930, 2008

SIMINSKI, A.; MANTOVANI, M.; REIS, M. S.; FANTINI, A. C. Sucessão florestal secundária no município de São Pedro de Alcântara, litoral de Santa Catarina: Estrutura e diversidade. Ciência Florestal, Santa Maria, v. 14, n. 1, p. 21-33, 2004.

SIMON, M. F.; GRETHER, R.; QUEIROZ, L. P.; SKEMA, C.; PENNINGTON, R. T.; HUGHES, C. E. Recent assembly of the Cerrado, a neotropical plant diversity hotspot, by in situ evolution of adaptations to fire. Proceedings of the National Academy of Sciences, Washington, v. 106, n. 48, p. 20359-20364, 2009.

STOCKAN, J. A.; LANGAN, S. J.; YOUNG, M. R. Investigating riparian margins for vegetation patterns and plant-environment relationships in northeast Scotland. Journal of Environmental Quality, Madison, v. 41, p. 364-372, 2012.

ZELLHUBER, A.; SIQUIERA, R. Rio São Francisco em descaminho: degradação e revitalização. Cadernos do CEAS, Salvador, v. 227, p. 7-32, 2007. 